\title{
Reducing indoor air pollution with a randomised intervention design - A presentation of the Stove Intervention Study in the Guatemalan Highlands
}

\author{
Tone Smith-Sivertsen ${ }^{1}$, Esperanza Díaz ${ }^{1}$, Nigel Bruce ${ }^{2}$, Anaite Díaz ${ }^{3}$, \\ Asheena Khalakdina ${ }^{4}$, Morten A. Schei ${ }^{5}$, John McCracken ${ }^{4,6}$, Byron Arana ${ }^{3}$, \\ Robert Klein ${ }^{7}$, Lisa Thompson ${ }^{4}$ and Kirk R. Smith ${ }^{4}$ \\ ${ }^{I}$ Department of Public Health and Primary Health Care, University of Bergen, Norway \\ ${ }^{2}$ Department of Public Health, University of Liverpool, United Kingdom \\ ${ }^{3}$ University del Valle, Guatemala City, Guatemala \\ ${ }^{4}$ Department of Environmental Health Sciences, University of California, Berkeley, USA \\ ${ }^{5}$ Centre for International Health, University of Bergen, Norway \\ ${ }^{6}$ Harvard University, Boston, USA \\ ${ }^{7}$ Centers for Diseases Control and Prevention, Atlanta, USA \\ Correspondence: Tone Smith-Sivertsen, Section for General Practice, Department of Public Health and Primary Health Care, \\ University of Bergen, N-5020 Bergen, Norway \\ E-mail: tone.smith-sivertsen@isf.uib.noＴelephone: 47-55 $586100 \quad$ Telefax: 47-55 586130
}

\begin{abstract}
Indoor air pollution from the burning of solid fuels (like wood and coal) in simple stoves is a global problem especially affecting people living in poor rural areas of the world. When typically burnt on open fires, the resulting indoor pollution levels may be orders of magnitude higher than levels recommended by international guidelines. The most important health effects seem to be acute lower respiratory infections (ALRI) in children and chronic obstructive pulmonary disease in women. So far, health risks from solid fuel use have only been studied with observational designs, often with poor assessment of exposures. Hence there is good reason to conduct a well-designed randomised intervention study.

In this randomised study, conducted in a poor rural community in Guatemala, indoor exposure burden in the intervention group is reduced by replacing open fires with new chimney stoves burning the same wood fuels. Participating households $(\mathrm{n}=534)$ all started the project with a child less than four months or a pregnant woman, and are being followed until the child reaches 18 months. At the end of follow-up, the control households receive their new stove. The main health outcome investigated is the incidence of ALRI in infants. Also, respiratory and cardiovascular health in women is studied. Preparations are also being made to study asthma/atopy in the children as they grow older. This study will define the relationship between exposure and disease more completely, quantify the impacts of reducing indoor air pollution and document the potential for prevention of ill-health that new stoves give. It is the first randomised controlled trial ever performed on health effects from combustion pollutants in normal populations.
\end{abstract}

\section{INTRODUCTION}

\section{Indoor smoke from solid fuels}

On a global basis, most indoor air pollution results from the burning of solid fuels for household cooking and heating. It is estimated that worldwide, approximately $50 \%$ of all households and up to $90 \%$ of rural households in the poorest developing countries utilize solid fuels for their everyday energy needs (1). Solid fuel use is defined as the combustion of coal or biomass (wood, dung, charcoal and crop residues). Commonly, open fires (Fig. 1) or inefficient simple stoves are used, often in poorly ventilated conditions. In such situations, solid fuel use causes substantial emissions of many health-damaging pollutants, including particu- late matter (PM) and carbon monoxide (CO). This may result in indoor air pollution exposures that are orders of magnitude higher than international guidelines, and higher than exposures encountered outdoors in even heavily polluted areas $(1,2)$. Women and their young-

\footnotetext{
Abbreviations

ALRI = acute lower respiratory infections; AURI = acute upper respiratory infections; $\mathrm{COPD}=$ chronic obstructive pulmonary disease; $\mathrm{PEF}=$ peak expiratory flow; $\mathrm{CO}=$ carbon monoxide; $\mathrm{PM}=$ particulate matter; $\mathrm{PM}_{2.5}=$ particulate matter of aerodynamic diameter less than $2.5 \square \mathrm{m} ; \mathrm{PM}_{10}=$ particulate matter of aerodynamic diameter less than $10 \square \mathrm{m}$; DALYs = disability-adjusted life years; RSV = respiratory syncytial virus; ETS $=$ environmental tobacco smoke
} 
gest children receive the highest exposure because of their activities in and around the house and kitchen.

In the past, and even today, most research emphasizes outdoor air pollution. Yet despite being somewhat neglected, indoor air pollution may pose a far greater health risk than outdoor air pollution. Although outdoor sources often dominate air pollution emissions, indoor sources frequently dominate air pollution exposures, since exposure is a function of both the concentration in an environment, and the person-time spent in the environment.

It has been estimated that globally, 1.6 million premature deaths or $2.6 \%$ of all ill-health (estimated as lost DALYs, disability-adjusted life years) is attributable to indoor smoke from solid fuels, solid fuel use ranking as one of the top ten risk factors for the global burden of disease $(1,3)$. There is strong evidence that solid fuel use is associated with chronic obstructive pulmonary disease (COPD) and lung cancer in women, and acute lower respiratory infections (ALRI) in young children $(2,4-7)$.

Acute respiratory infections account for a remarkable $6.4 \%$ of the global burden of disease, and ALRI is the most important cause of death among children under five years of age in developing countries (3). ALRI in this age group is also the largest single category of deaths (64\%) and DALYs (81\%) from indoor air pollution, estimated to be responsible for about one million premature deaths annually in children under five (5).

COPD is currently the sixth leading cause of death in the world (3), and the prevalence of COPD is increasing (8). It is projected that by 2020 COPD will rank fifth as a worldwide burden of disease (9). Globally, it is estimated that $22 \%$ of the disease burden caused by COPD can be attributed to indoor smoke from solid fuels, while in developing countries, indoor smoke is responsible for as much as $40-45 \%$ of the COPD burden in women (3). This strongly contrasts the situation in developed countries, where most COPD is due to smoking.

Besides ALRI, lung cancer and COPD, there is moderate evidence of associations of solid fuel use with tuberculosis, asthma and cataracts, and indications of associations with low birth weight, ischaemic heart disease, nasopharyngeal and laryngeal cancer, cervical neoplasia and trachoma $(1,2,10)$. Burns that result from clothes catching fire or children falling into the fireplace is another important health hazard related to open fires (11).

\section{Rationale for an intervention study}

From the above, it may seem obvious to anyone that indoor smoke from solid fuels is a global health problem and that interventions should be made to reduce the exposure in developing countries. However, in countries where not even basic needs like vaccines and clean water can be met with the available resources, any intervention to promote health has to be proven to be highly effective. Hence there is a need for better risk estimates and for quantification of the health effects obtained by the intervention programme.

To date, all studies on health effects of indoor smoke have had observational designs, and thus may be biased by unidentified confounders. Moreover, few of the studies have actually measured exposure, relying instead on proxies such as time spent near the fire/stove. This increases the chances of serious misclassification of exposure, and means that very little information is available to quantify the relationships between exposure and risk. Consequently, there is a strong case for carrying out a well-designed intervention study where exposure-assessment holds a high quality. A randomised trial will, if the randomisation is successful, eliminate the problem of confounding, and it is the one design potentially providing strongest evidence of causation. It will define the relationship between exposure and disease more completely and show the benefit of potential interventions more convincingly.

\section{Aims of the study}

The main aims of the Stove Intervention Study in the Guatemala Highlands are to 1) conduct a randomised intervention trial which will increase confidence in air pollution risk estimates; and 2) extend the exposureresponse curve for PM to higher chronic levels than has ever been done within a single population, thus assisting efforts to understand the physiological mechanisms of PM impact.

To do so, a previously proven exposure-reduction technology (chimney stoves) was introduced randomly in a highly exposed population to study differences in the intervention versus control groups for the following main health outcomes:

a) Incidence of acute lower respiratory infections (ALRI) in young children (less than 18 months)

b) Lung health in women (lung function, prevalence of chronic respiratory symptoms, incidence of acute respiratory symptoms)

c) Prevalence of asthma and allergies in children

d) Heart rate variability in older women

e) Prevalence of low birth weight

f) Burns in children

\section{The international collaboration and funding}

The intervention trial has been planned since 1984, when an international group of scientists met to explore the research implications of the first published assessment of household cooking exposures, done in India in 1981 (12). Initially, unsuccessful proposals were submitted to conduct the trial in Nepal, but in the early 1990s, under the auspices of a WHO expert committee formed to find the best site globally, other sites were examined. Guatemala was chosen and a series of pilot studies initiated to characterize the site sufficiently to mount a successful proposal. 
The current Guatemala stove intervention study is the result of close collaboration between scientists at the University of California Berkeley (professor Kirk R. Smith, principal investigator), University del Valle Guatemala, the University of Liverpool and the University of Bergen. The group in Bergen is responsible for the study of lung health in women (SmithSivertsen, Díaz) and asthma/allergies in children (Schei). Researchers at the WHO, Geneva are also engaged in the project.

The major part of the study is funded by the National Institutes of Health in the US by a 1.8 mill USD grant as well as approximately $\$ 150,000$ from private foundations. Much of the pilot work in Guatemala was funded by resources obtained by WHO, which also helps support parts of the child health study. The Norwegian Research Council funds the study of lung health in women and asthma/allergies in children.

\section{EXPERIMENTAL DESIGN AND METHODOLOGY}

Extensive pilot work has been carried out to ensure feasibility of the methods. All published and unpublished pilot studies can be found on the project website (http://ehs.sph.berkeley.edu/guat/). After a year-long preparatory period, the trial itself started in October 2002 and will end in December 2004.

\section{Field site and population}

The study population is a poor, rural indigenous Mayan-Indian community living in San Marcos district. The principal language spoke in the area is Mam, the second largest language group among Mayan Indians. In this area, where smoking is uncommon, PM exposures are dominated by open wood-burning cookstoves (Fig. 1) producing daily 24-hour $\mathrm{PM}_{2.5}$ indoor levels of $1000 \square \mathrm{g} / \mathrm{m}^{3}$ and higher, i.e., some 60 times more than typical national standards set to protect health. The community has a high infant mortality rate (estimated at $80 / 1000$ or higher), high incidence/ mortality from ALRI, prevalence of low birth weight of $15-20 \%$, and a nearly universal dependence on wood fuel. In these respects the population is typical of many poor countries where ALRI remains a priority and will therefore have reasonable generalisability and wide relevance.

The population lives scattered in small settlements, mainly depending on non-monetary economy through growth of maize and keeping of domestic animals. Illiteracy is common, especially among women, and many of them can not speak the official national language, Spanish.

\section{The intervention}

The randomly chosen intervention group was offered a new woodstove, the locally produced Plancha (Fig. 2), which is constructed using bricks and concrete blocks, and has a metal chimney that expels the smoke outside the house. Pilot work has confirmed that the Plancha meets all cooking and space-heating needs and achieves a sustainable 4-5 fold reduction in indoor pollution levels $(13,14)$. It is well-liked by people in this community, and is the stove of choice for both independent buyers and community stove programmes in the area. The reason everyone in the area does not have one is cost, as the approximate US\$100 price is prohibitive for most families.

\section{Sampling and recruitment}

An initial census survey of the study area was used to identify and map all homes with open fires. Households with a 0-4 month old child (index child) or a pregnant woman (index child not yet born) were invited, altogether 269 children and 266 pregnant women from 534 households were recruited. The households are followed until the index child reaches 18 months of age.

The women participating in the respiratory health study $(\mathrm{n}=505)$ are the mothers of the index children, and the children participating in the asthma/allergy study are both the index children and their siblings aged 15 years and younger (siblings: $n=1410$ ). Participants in the heart-rate variability study $(n=117)$ are women over 40 years of age living in the home, usually the grandmother of the index child.

A sample size of 500 children (630 child years of follow-up) was determined to detect a $20 \%$ change in ALRI incidence rate of 0.5 episodes per child per year (power $=0.8 ; \mathrm{a}=5 \%$ ). This sample size has also been calculated to be adequate for the investigation of lung health in their mothers and asthma/allergies in children.

\section{Randomisation, intervention and control groups}

Following recruitment and informed consent, randomisation was carried out in pre-sized blocks of 10 households. The randomisation was not stratified by village, but since the field team moved through villages one by one during recruitment, this mimicked blocking by village. The intervention group received the Plancha stove. Advice and training were given on safe, efficient use of the Plancha, including maintenance. The control group continued to use the traditional open fire, in effect with no change to usual practice until the index child "retires" from the project (reaches 18 months). All control households are offered a stove on retirement.

\section{Fieldwork, personnel and quality assurance}

The fieldwork takes place through home visits by fieldworkers. Any member of the household in need of further investigation or treatment are referred to a local health centre to be seen by a study physician. The field staff members are recruited locally, because it is crucial that they speak both Spanish and Mam. They 
have all received thorough training, have taken part in pilot studies, and are under regular supervision in the field. All data forms are checked by supervisors every day for errors and missing information.

\section{Baseline assessment}

Following consent a detailed household survey was carried out (Table 1). Interview (usually with the mother) assessed social, demographic and economic factors, detailed fuel use patterns, house characteristics, smoking habits etc. If the index child was born, its height/length was measured, feeding patterns recorded, and assessment of personal exposure to $\mathrm{CO}$ was done for both child and mother (see below).

\section{Health outcomes assessment}

An overview of the assessment of health outcomes and exposure has been given in Table 1.

\section{Acute lower respiratory infections (ALRI) and other} health outcomes in index children

Child health outcomes are assessed through weekly visits until the child reaches 18 months. The principal health outcome measure is ALRI, defined according to WHO criteria for community studies.
The fieldworkers are trained to ask for key symptoms and examine the child for key signs according to the WHO Integrated Management of Childhood Illnesses (IMCI) case-finding techniques for acute respiratory infections, wheeze, diarrhoea, malnutrition, and other serious childhood illnesses (15). In addition, the assessment includes burns and scalds. Children meeting the IMCI criteria for referral for medical opinion and treatment are examined by one of the study physicians at a local health centre, leaving the physicians blinded to the intervention. Children with signs of ALRI have a chest X-ray and pulse oximetry taken, as well as a nasal swab for determination of respiratory syncytial virus (RSV). Children who are too ill to be treated at home are transferred to the nearest hospital with which the project has close cooperation.

Birth weight is registered in all children that are born into the study by the project team. Weight and height are measured every three months to assess growth and nutritional status.

The cause of any deaths among study children is assessed based on standard verbal autopsy procedures. This procedure involves a standardized structured interview with the family around six weeks after the death to establish the cause.

Table 1. Overview of the Stove Intervention Study.

\begin{tabular}{|c|c|c|c|}
\hline & MAIN OUTCOMES & BASELINE ASSESSMENT & EXPOSURE \& HEALTH ASSESSMENT \\
\hline $\begin{array}{c}\text { Household } \\
\mathrm{n}=534\end{array}$ & & $\begin{array}{l}\text { Background characteristics: } \\
\text { - Family structure } \\
\text { - Socioeconomy } \\
\text { - Housing conditions } \\
\text { - ETS } \\
\text { - Fuel use }\end{array}$ & $\begin{array}{l}\text { Intensive group }(\mathrm{n}=78) \\
\text { - Time-activity assessment } \\
\text { - PM/CO monitoring inside/outside }\end{array}$ \\
\hline $\begin{array}{c}\begin{array}{c}\text { Index } \\
\text { children } \\
(0-18 \text { months }) \\
n=528\end{array} \\
\text { (n) }\end{array}$ & $\begin{array}{l}\text { ALRI } \\
\text { Asthma/allergy } \\
\text { Birthweight } \\
\text { Burns }\end{array}$ & $\begin{array}{l}\text { CO monitoring tubes } \\
\text { Height, weight } \\
\text { Feeding patterns }\end{array}$ & $\begin{array}{l}\text { ALRI, wheeze \& burns weekly } \\
\text { Height and weight every } 3 \text { month } \\
\text { CO tubes every } 3 \text { month } \\
\text { Birthweight } \\
\text { (Future plans: Skin prick testing and lung } \\
\quad \text { function testing) }\end{array}$ \\
\hline $\begin{array}{c}\text { Mothers } \\
(15-50 \text { years }) \\
n=505\end{array}$ & $\begin{array}{l}\text { Lung function } \\
\text { Respiratory symptoms } \\
\text { Eye, head, back } \\
\quad \text { symptoms }\end{array}$ & $\begin{array}{l}\text { CO monitoring tubes } \\
\text { Lung function testing } \\
\text { Chronic symptoms } \\
\quad \text { questionnaire }\end{array}$ & $\begin{array}{l}\text { Acute respiratory symptoms weekly } \\
\text { CO tubes every } 6 \text { month } \\
\text { At } 6-12-18 \text { months: } \\
\text { - Lung function testing } \\
\text { - Chronic symptoms questionnaire } \\
\text { - CO exhaled breath } \\
\text { - CO real-time monitor (20\%) } \\
\text { PEF study (women with symptoms) 1week }\end{array}$ \\
\hline $\begin{array}{c}\text { Siblings } \\
(\leq 15 \text { years }) \\
n=1410\end{array}$ & $\begin{array}{l}\text { Asthma/allergy } \\
\text { Burns }\end{array}$ & Questionnaire & $\begin{array}{l}\text { Questionnaire (ISAAC) 6-12-18 months } \\
\text { (Future plans: Skin prick testing and lung } \\
\text { function testing) }\end{array}$ \\
\hline $\begin{array}{c}\text { Older women } \\
\begin{array}{c}>40 \text { years }) \\
n=117\end{array}\end{array}$ & $\begin{array}{l}\text { Heart rate variability } \\
\text { Lung health }\end{array}$ & & $\begin{array}{l}\text { Holter monitoring } \\
\text { Blood pressure } \\
\text { Lung function testing } \\
\text { CO exhaled breath }+ \text { Monitoring of PM and } \\
\quad C O \text { (personal and in kitchen) } \\
\text { Questionnaire }\end{array}$ \\
\hline
\end{tabular}




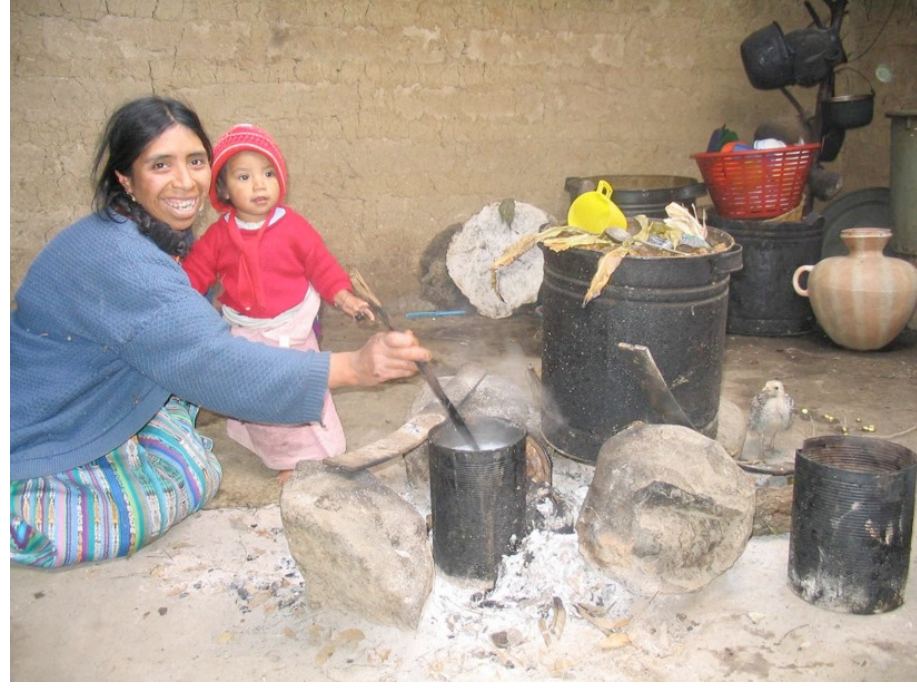

Figure 1. Woman cooking on an open fire (photo Anaite Díaz).

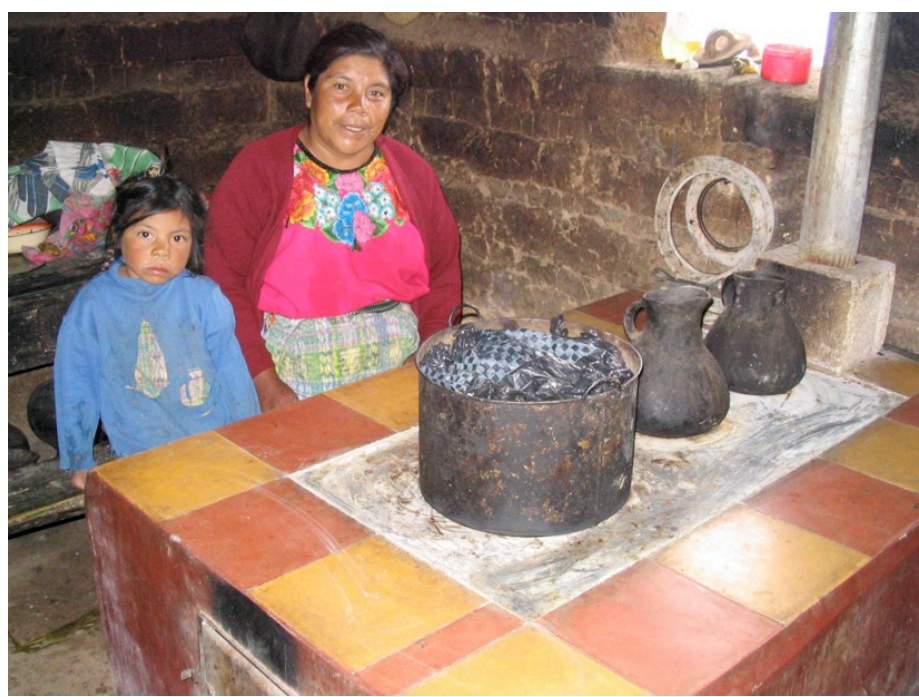

Figure 2. The Plancha chimney stove, Guatemala (photo Anaite Díaz).

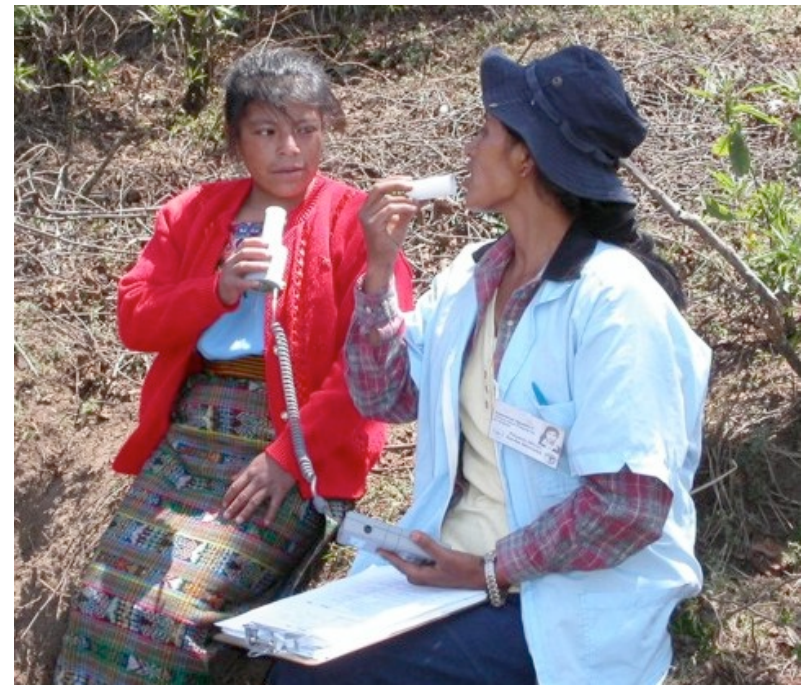

Figure 3. Study woman is instructed in the spirometry procedure (photo Tone Smith-Sivertsen).

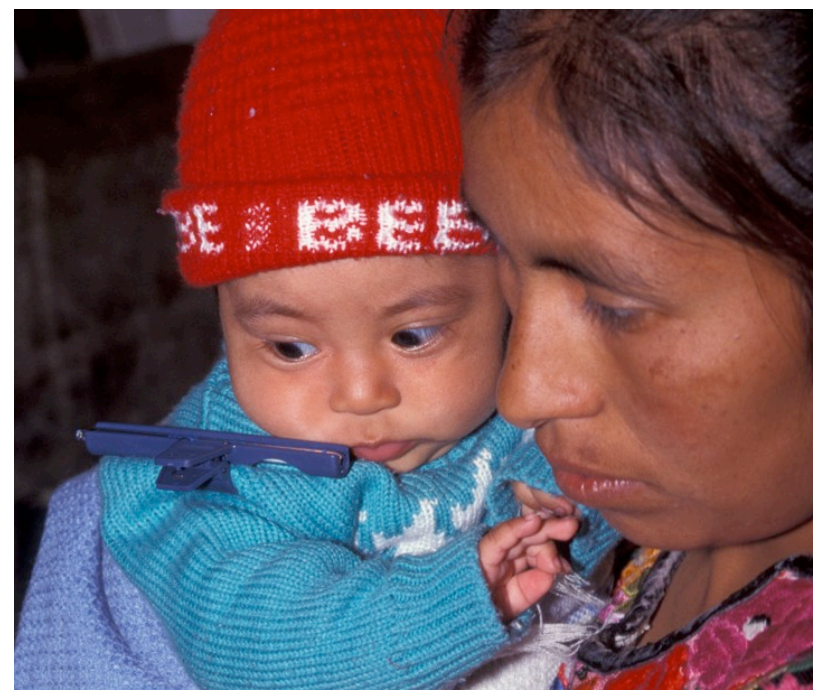

Figure 4. Child wearing a personal CO monitoring tube (photo Nigel Bruce).
Lung health in women

This study will show whether young non-smoking adult women with early signs of COPD may experience a relief from their symptoms by reducing their exposure burden.

Chronic respiratory symptoms indicating COPD or asthma, such as cough and phlegm, wheeze and shortness of breath are assessed by means of a questionnaire interview at baseline and every sixth month thereafter until the woman leaves the study (i.e. two or three follow-up assessments). The lung questions are based on standard MRC, IUATLD and ISAAC questions for respiratory diseases (16-18). The original format of key cough and phlegm questions were, however, not usable, and they were modified through extensive local piloting to versions for which the time patterns of symptoms were understood by the women.
A study of the repeatability of the questions is currently being undertaken.

Lung function is measured with a Micromedical Microloop spirometer at the same visits as the questionnaire interview takes place (Fig. 3). The guidelines by the American Thoracic Society are followed (19).

Acute upper and lower respiratory symptoms are assessed by means of a short questionnaire every week in connection with the weekly surveillance for child health.

Peak expiratory flow (PEF) was investigated in a sub-study $(n=89)$ of women who all reported either wheeze, tightness in the chest, chronic cough or chronic phlegm at baseline. The women kept a diary for seven days where they recorded three PEF results in the morning and in the evening. This study will tell us whether symptomatic women of the intervention group 
have better PEF values and lower PEF variability in measurements than the control group.

\section{Heart rate variability}

Heart rate variability is studied by means of Holter monitoring in older ( $>40$ years) women (Table 1$)$. There is consistent evidence that exposures to outdoor particulate pollution in developed countries is associated with increased daily cardiovascular mortality and morbidity, and several studies have shown an association with indicators of autonomic function of the heart including increased heart rate, decreased heart rate variability, and increased cardiac arrhythmias (29).

\section{Asthma and atopy in siblings}

The mother is asked for symptoms of asthma, eczema and hayfever in all of the siblings of the index child aged 15 years and younger. The ISAAC questionnaire is used for this purpose (18). The mother is asked every six months whether any of her children less than nine years old have had burns or scalds.

\section{Exposure assessment}

Careful assessment of pollution exposure is vital because a) it enables assessments of dose-response relationships, b) it reduces the chance of misclassification due to differences in performance of the stoves; house conditions; and household behaviours, and c) it enables comparisons to exposure in other parts of the world.

Levels of exposure to indoor air pollutants are assessed for each index child and study woman periodically during the follow-up period (Table 1). Although small particles are thought to be the best indicator of the health risk of combustion-related pollution, because of the practical difficulties of using noisy air sampling pumps or other PM monitoring devices, $\mathrm{CO}$ exposures are also measured as a proxy for PM exposure. $\mathrm{CO}$ has been shown in several studies to be highly correlated with PM levels as well as being highly reproducible in settings such as this $(21,22)$. Personal monitoring with small CO diffusion tubes clipped to the clothing is used for 48 hours (Fig. $4)$; this is repeated every third month for the child and every sixth month for the mother. In the mother, $\mathrm{CO}$ in exhaled breath is measured together with the sixmonthly lung health assessments as a proxy for recent exposure. In $20 \%$ of the women, also real-time CO exposure is measured 48 hours prior to spirometry. This is done with personal electro-chemical CO moni- tors, set to record at 1-minute intervals for 24 hours. Doing this, the impact of peaks of exposure on lung function can be examined.

In a random sub-sample of 78 study households more detailed measurements of the personal and indoor levels of $\mathrm{PM}\left(\mathrm{PM}_{2.5}\right.$ and $\left.\mathrm{PM}_{10}\right)$ and $\mathrm{CO}$ are undertaken, as well as time-activity patterns of the mother and child. A range of different exposure monitoring devices are being employed. Outdoor pollutant concentrations are also measured periodically for each village in an attempt to quantify the impact of outdoor pollutants on indoor air quality and vice versa.

\section{ETHICS}

The study has been approved by the respective ethics committees in Berkeley, Guatemala, Liverpool, Atlanta (CDC), Geneva (WHO), and Bergen. An independent international data safety and monitoring board (DSMB) consisting of relevant expertise has been assembled who convene regularly to discuss the progress of the project, in particular adverse events that may occur and safety issues for the participants. They have the power to stop the project if they think the participants are being put unduly at risk and to determine when database codes can be broken so that outcomes can be linked to intervention status.

\section{SIGNIFICANCE OF THE STUDY}

This is the first randomised controlled trial ever on health effects of solid fuel use. Randomised studies provide the strongest evidence of causation. Besides defining the relationship between exposure and disease more completely, this study will quantify the impacts of reducing air pollution and document the potential for prevention that new stoves give. In a broader perspective, the results from this study may influence future decision making on preventive health priorities in developing countries.

\section{ACKNOWLEDGEMENTS}

We thank the staff at the field site for their excellent work; special appreciation goes to Eduardo Canuz, Fredy Agustin, Nazario Lopez and Rudinio Acevedo. Martin Weber (WHO) is acknowledged for his technical advice, and Alisa Jenny (UC Berkeley) for her administrative support. We also want to express our gratitude to the San Marcos Health Area and the Ministry of Health in Guatemala for their support. Finally warm thanks are offered to the mothers and families who have participated in the study.

\section{REFERENCES}

1. Smith KR, Mehta S, Maeusezahl-Feuz M. Indoor smoke from solid fuels. In: Ezzati M, Rodgers AD, Lopez AD, Murray CLJ, editors. Comparative quantification of health Risks: Global Burden of Disease due to Selected Major Risk Factors. Geneva: World Health Organization, 2004: 1437-1495.

2. Bruce N, Perez-Padilla R, Albalak R. Indoor air pollution in developing countries: a major environmental and public health challenge. Bull World Health Organ 2000; 78 (9): 1078-1092. 
3. WHO. World Health Report 2002. Geneva, World Health Organization.

4. Variations in the prevalence of respiratory symptoms, self-reported asthma attacks, and use of asthma medication in the European Community Respiratory Health Survey (ECRHS). Eur Respir J 1996; 9 (4): 687-695.

5. Smith KR, Samet JM, Romieu I, Bruce N. Indoor air pollution in developing countries and acute lower respiratory infections in children. Thorax 2000; 55 (6): 518-532.

6. Perez-Padilla R, Regalado J, Vedal S, Pare P, Chapela R, Sansores R, et al. Exposure to biomass smoke and chronic airway disease in Mexican women. A case-control study. Am J Respir Crit Care Med 1996; 154 (3 Pt 1): 701-706.

7. Ezzati M, Kammen D. Indoor air pollution from biomass combustion and acute respiratory infections in Kenya: an exposure-response study. Lancet 2001; 358 (9282): 619-624.

8. Pauwels RA, Buist AS, Calverley PM, Jenkins CR, Hurd SS. Global strategy for the diagnosis, management, and prevention of chronic obstructive pulmonary disease. NHLBI/WHO Global Initiative for Chronic Obstructive Lung Disease (GOLD) Workshop summary. Am J Respir Crit Care Med 2001; 163 (5): 1256-1276.

9. Murray CJ, Lopez AD. Evidence-based health policy - lessons from the Global Burden of Disease Study. Science 1996; 274 (5288): 740-743.

10. Velema JP, Ferrera A, Figueroa M, Bulnes R, Toro LA, de Barahona O, et al. Burning wood in the kitchen increases the risk of cervical neoplasia in HPV-infected women in Honduras. Int J Cancer 2002; 97 (4): 536 541.

11. Ahuja RB, Bhattacharya S. Burns in the developing world and burn disasters. BMJ 2004; 329 (7463): $447-$ 449.

12. Smith KR, Aggarwal AL, Dave RM. Air pollution and rural biomass fuels in developing countries: A pilot village study in India and implications for research and policy. Atmos Environ 1983; 17 (11): 2343-2362.

13. Naeher LP, Leaderer BP, Smith KR. Particulate matter and carbon monoxide in highland Guatemala: indoor and outdoor levels from traditional and improved wood stoves and gas stoves. Indoor Air 2000; 10 (3): 200205.

14. Albalak R, Bruce N, McCracken JP, Smith KR, De Gallardo T. Indoor respirable particulate matter concentrations from an open fire, improved cookstove, and LPG/open fire combination in a rural Guatemalan community. Environ Sci Technol 2001; 35 (13): 2650-2655.

15. WHO (UNICEF). Integrated Management of Childhood Illness, 1997. Geneva, WHO.

16. Toren K, Brisman J, Jarvholm B. Asthma and asthma-like symptoms in adults assessed by questionnaires. A literature review. Chest 1993; 104 (2): 600-608.

17. Bai J, Peat JK, Berry G, Marks GB, Woolcock AJ. Questionnaire items that predict asthma and other respiratory conditions in adults. Chest 1998; 114 (5): 1343-1348.

18. Asher MI, Weiland SK. The International Study of Asthma and Allergies in Childhood (ISAAC). ISAAC Steering Committee. Clin Exp Allergy 1998; 28 Suppl 5: 52-66.

19. Standardization of Spirometry, 1994 Update. American Thoracic Society. Am J Respir Crit Care Med 1995; 152 (3): 1107-1136.

20. Dockery DW. Epidemiologic evidence of cardiovascular effects of particulate air pollution. Environ Health Perspect 2001; 109 Suppl 4: 483-486.

21. Naeher LP, Smith KR, Leaderer BP, Mage D, Grajeda R. Indoor and outdoor PM2.5 and CO in high- and low-density Guatemalan villages. J Expo Anal Environ Epidemiol 2000; 10 (6 Pt 1): 544-551.

22. Joshi V, Venkaraman C, Ahuja DA. Emissions from burning biofuels. Environ Manage 1989; 13 (6): $763-772$. 